\title{
Reflexões jurídico-institucionais a respeito do território da Flona do Jamanxim: avanços, recuos e conflitos atuais
}

\section{Legal-institutional reflections on Flona do Jamanxim territory: advances, retreats and current conflicts}

\author{
Suelen Maria Costa Monteiro ${ }^{1}$
}

\begin{abstract}
Resumo: $O$ presente trabalho apresenta e discute as questões de fundo que problematizam a proposta de alteração dos limites da Floresta Nacional do Jamanxim, no município de Novo Progresso, região sudoeste do Pará, por meio do Projeto de Lei 8.107/2017, de iniciativa do Chefe do Poder Executivo Federal. Em relevo, sinaliza-se interesses eminentemente econômicos e o benefício a agentes criminosos, que se apropriam de terras públicas ilegalmente, por meio de grilagem. Neste contexto, a tutela de proteção ambiental, concebida sob a perspectiva de um grande mosaico de conservação, visando conter os impactos provocados pelo asfaltamento da BR-136, no Plano BR-163 Sustentável, vem sendo violada, posto a desproteção de significativas áreas da floresta. Para subsidiar a temática serão usados documentos oficiais de órgãos estatais, responsáveis, inclusive pelo gerenciamento da referida unidade de conservação (ICMBio); assim como matérias jornalísticas disponibilizadas em sítios eletrônicos de instituições governamentais e não governamentais, além de referencial teórico especializado na área deste estudo. Neste contexto, a temática abordada reforça a necessidade de acompanhamento das discussões em torno da referida unidade de conservação, dado o perigoso e iminente precedente de desproteção ambiental.
\end{abstract}

Palavras-chave: Unidade de Conservação, Flona Jamanxim, Tutela Ambiental.

\begin{abstract}
This paper presents and discusses the fundamental issues that problematize the proposal to change the National Forest of Jamanxim, in the municipality of Novo Progresso, in the southwest region of Pará, through Law Project 8.107 / 2017, initiated by the Chief of Executive Branch Federal. Emphasis is placed on eminently economic interests and the benefit of criminal agents, who illegally appropriated public lands by means of grilagem. In this context, the protection of the environment, conceived from the perspective of a large conservation mosaic, aimed at containing the impacts caused by the asphalting of BR-136, in the BR-163 Sustainable Plan, has been violated, given the lack of protection of significant areas of forest. In order to subsidize the theme, official documents of state organs, responsible, including the management of said conservation unit (ICMBio), will be used; as well as journalistic material made available in electronic sites of governmental and non-governmental institutions, as well as specialized theoretical reference in the area of ??this study.
\end{abstract}

Keywords: Conservation Unit, Flona Jamanxim, Environmental Protection.

\footnotetext{
${ }^{1}$ Mestranda em Ciências da Sociedade pela da Universidade Federal do Oeste do Pará. Graduada em Direito. E-mail: suelen.mcm@ufopa.edu.br
} 


\section{Introdução}

Este artigo discute como a redução dos limites territoriais da Floresta Nacional do Jamanxim para conversão em Área de Proteção Ambiental (APA), nos termos do Projeto de Lei 8.107/2017, de iniciativa do Chefe do Poder Executivo Federal e atualmente em tramitação no Congresso Nacional, dissocia-se, em termos gerais, de interesses legítimos de ocupação da terra e da resolutividade de demandas socioeconômicas e fundiárias locais. O ensaio não pretende esvaziar o tema, que possui imbricada e complexa relação econômica, política e social, com repercussão inclusive no âmbito internacional.

A Flona Jamanxim foi criada em 2006, juntamente com outras Unidades de Conservação ${ }^{2}$, estando prevista no portfólio de iniciativas do Plano de Desenvolvimento Regional Sustentável ${ }^{3}$ para a área de influência da Rodovia BR-163 (Cuiabá-Santarém). objetivo era mitigar os impactos provocados pelo asfaltamento da rodovia, a partir de um grande "escudo protetor", formado pelo mosaico de unidades de conservação.

Neste contexto, propomo-nos discutir sucintamente questões cruciais visivelmente expostas diante das iniciativas de redução dos limites da referida Flona, a saber: a finalidade protetiva para a qual foi criada a área protetiva não estaria sendo violada quando da sua alteração, uma vez que integra o mosaico protetor? Quais as questões de fundo que fragilizam a tutela protetiva ambiental?

O Decreto Presidencial, sem número, publicado no D.O.U em 14/02/2006, criou a Floresta Nacional do Jamanxim, com extensão de 1.301.120 hectares. A unidade de conservação pertencente ao Grupo de Uso Sustentável (categoria dada pelo Sistema

\footnotetext{
${ }^{2}$ As novas unidades de conservação de uso sustentável somam 4,9 milhões de hectares, incluindo a Floresta Nacional do Jamanxim (1.301 mil hectares), a Floresta Nacional do Crepori (740 mil hectares), a Floresta Nacional Amana (540 mil hectares), a Floresta Nacional do Trairão (257 mil hectares) e a Área de Proteção Ambiental do Tapajós (2.059 mil hectares), esta última envolvendo a quase totalidade da Reserva Garimpeira do Tapajós. As novas unidades de conservação de proteção integral somam 1,9 milhões de hectares, compreendendo a Reserva Biológica Nascentes da Serra do Cachimbo (342 mil hectares), o Parque Nacional do Jamanxim (859 mil hectares), o Parque Nacional do Rio Novo (537 mil hectares) e a ampliação do Parque Nacional da Amazônia (167 mil hectares). (Plano BR-163 Sustentável. Casa Civil da Presidência da República, 2006).

${ }^{3}$ Trata-se, sobretudo, de um plano estratégico de desenvolvimento regional, referenciado no Plano Amazônia Sustentável (PAS), que estabelece novos paradigmas para o desenvolvimento da Amazônia Brasileira, mas é também um plano operacional, referenciado à implementação de ações e políticas governamentais em toda a região. A elaboração do Plano BR-163 Sustentável esteve a cargo do Grupo de Trabalho Interministerial (GTI) instituído por Decreto em 15 de março de 2004, coordenado pela Casa Civil da Presidência da República e integrado por vinte Órgãos Federais - Ministérios e Órgãos da Presidência da República. (Plano BR-163 Sustentável. Casa Civil da Presidência da República, 2006).
} 
Nacional de Unidades de Conservação - SNUC) e tem jurisdição na Amazônia Legal, sob competência da instância federal. Atua como órgão gestor o Instituto Chico Mendes de Conservação da Biodiversidade (ICMBio) e sua área de incidência abrange o município de Novo Progresso, localizado no sudoeste do estado do Pará.

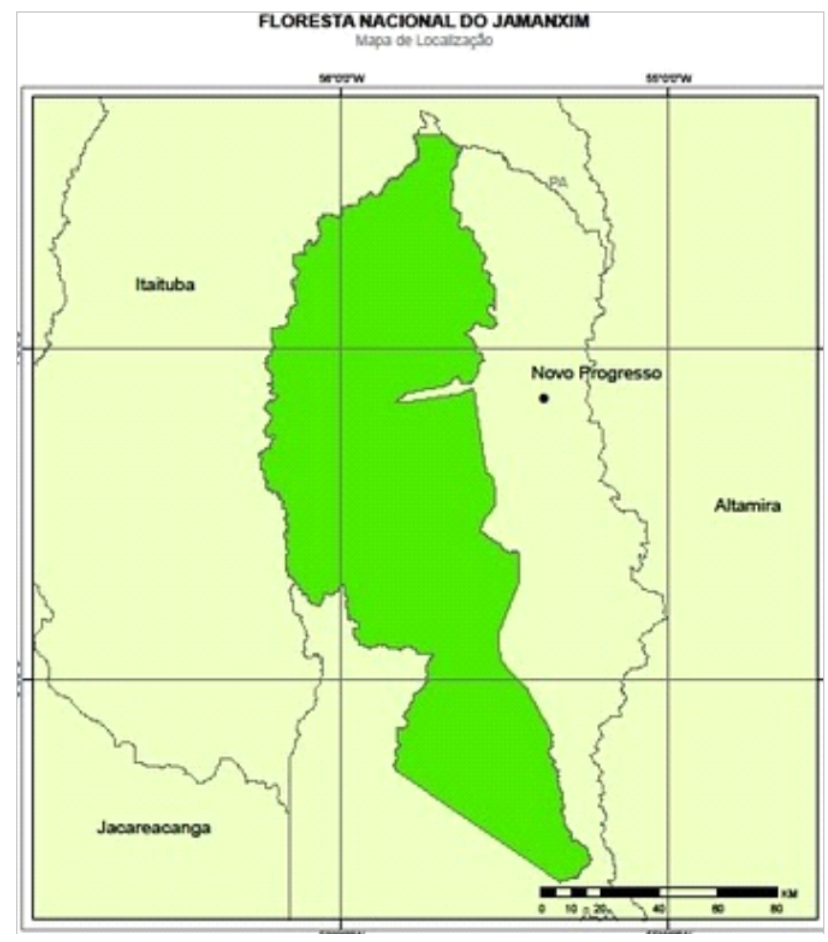

Figura 1. Localização da Floresta Nacional do Jamanxim e sua interseção com o Município de Novo Progresso, Pará. Fonte: Folha Verde News (2017).

Importante ressaltar que no Brasil o conceito de meio ambiente foi trazido pela Política Nacional de Meio Ambiente, Lei 6.938 de 31/08/1981 e posteriormente incorporado pela Constituição Federal de 1988 (AMADO, 2017). Canotilho (1994) pondera que a Constituição tentou organizar a proteção ambiental segundo uma visão global do objeto da tutela, criando um "dever constitucional geral de não degradação". Nas palavras do Ministro do Superior Tribunal de Justiça, Antônio Herman Benjamin:

Trata-se de dever constitucional autossuficiente e com força vinculante plena, dispensando, na sua aplicação genérica, a atuação do legislador ordinário. É, por outro lado, dever inafastável, tanto pela vontade dos sujeitos privados envolvidos, como a pretexto de exercício da discricionariedade administrativa. Vale dizer: é dever que, na estrutura do edifício jurídico, não se insere na esfera de livre opção dos indivíduos, públicos ou não. (HERMAN, 2011).

Thomé e Medeiros (2016) afirmam que a CRFB/88 exerce um papel de divisor de águas, pois muito embora já existissem aéreas protegidas desde 1973 (ano de criação 
do Parque Nacional de Itatiaia), e em que pese a Lei 6.938/1981 tenha permitido erigir um agrupamento de unidades de conservação, estas previsões eram casuísticas, sem rumo certo e carente de recursos e políticas ambientais.

A Constituição de 1988 previu a regulamentação de espaços territoriais especialmente protegidos, sendo criada, posteriormente, a Lei 9.985/2000, que institui o Sistema Nacional de Unidades de Conservação da Natureza - SNUC. As unidades foram divididas em dois grandes grupos, com características específicas: Unidades de Proteção Integral e Unidades de Uso Sustentável, ambas voltadas a um ou vários objetivos trazidos pelo SNUC, respeitada sempre a primazia da finalidade conservacionista. Para o Ministro Herman Benjamin:

A criação de Unidades de Conservação não é um fim em si mesmo, vinculada que se encontra a claros objetivos constitucionais e legais de proteção da Natureza. Por isso, em nada resolve, freia ou mitiga a crise da biodiversidade - diretamente associada à insustentável e veloz destruição de habitat natural -, se não vier acompanhada do compromisso estatal de, sincera e eficazmente, zelar pela sua integridade físico-ecológica e providenciar os meios para sua gestão técnica, transparente e democrática. A ser diferente, nada além de um "sistema de áreas protegidas de papel ou de fachada" existirá, espaços de ninguém, onde a omissão das autoridades é compreendida pelos degradadores de plantão como autorização implícita para o desmatamento, a exploração predatória e a ocupação ilícita. (REsp 1071741/SP, Rel. Ministro HERMAN BENJAMIN, SEGUNDA TURMA, julgado em 24/03/2009, DJe 16/12/2010). (Grifo do autor).

Neste contexto, a finalidade protetiva da norma, encartada na própria Constituição e na legislação infraconstitucional, e colmatada no ato de criação da Floresta Nacional do Jamanxim, objeto deste estudo, traz expressamente sua ratio "impedir ações degradadoras do meio ambiente como o desmatamento, a caça e a pesca predatórias, promovendo o desenvolvimento do uso sustentável dos recursos naturais e as pesquisas científicas." (Relatório final, 2009, ICMBio).

No entanto, o debate aqui oportunizado pauta-se a demonstrar que a consecução dos objetivos perseguidos pela norma, em termos práticos, não alcançou sua efetividade, e, contrariamente, sofre o revés daqueles que articulam, planejam e lideram iniciativas desprovidas de compromisso e responsabilidade socioambiental.

Assim, os dados que fundamentam nossa discussão são oriundos de relatório do órgão gestor da Flona (ICMBio), manifestação de instituições públicas, como o Ministério 
Público Federal e organizações não governamentais, a exemplo do Instituto Socioambiental (ISA), além da literatura especializada e outros documentos oficiais.

O trabalho está estruturado, além desta breve introdução, em uma concisa contextualização histórica das políticas de desenvolvimento concebidas para a região amazônica, as iniciativas estatais propostas para a alteração da Flona Jamanxim, as principais questões de fundo que problematizam à temática, compreendendo a prática de crimes ambientais - desmatamento e grilagem de terras.

\section{Breve contextualização histórica}

Para Torres et al. (2017) é preciso analisar criticamente o contexto histórico sob o qual se constrói as problemáticas em torno da criação da Flona Jamanxim - grilagem de terras públicas e a consequente degradação ambiental. Segundo o pesquisador, há intrínseca relação entre as políticas desenvolvimentistas para a região amazônica e a criação do mosaico de conservação. Trata-se de um processo dialógico que também se relaciona com a proposta de alteração da unidade de conservação, pautada não apenas por interesses legítimos (de moradores que já ocupavam áreas antes da criação da FNJ em 2006), mas também por interesses de poderosos latifundiários. Já diria Walter Benjamin (traduzido por LÖWY, 2005) "a visão positivista do progresso - ordenada, natural e linear - é equivocada".

Nesta visão Cardoso e Muller (2008), alegam que a penetração geográfica na Amazônia e a história da região devem ser compreendidas a partir do processo de expansão do capitalismo, em função da forma, ritmo e volume da acumulação ocorrida nas demais regiões brasileiras. Assim, considerando que o capital nada mais é do que uma relação social, a expansão do capitalismo na Amazônia depende da forma concreta que aquela relação social assume.

Então não causa estranheza o fato de a Amazônia sempre ter protagonizado discursos pautados pela lógica da conquista, do capital. Vale ressaltar que a ocupação da Amazônia pela colonização portuguesa se deu por interesses políticos. Sendo facilmente detectados pelas ações do Estado colonial em sua legislação, no modo de produção e de exploração da mão-de-obra praticada nos povoados pelas missões religiosas espalhadas 
no território do Grão-Pará e Maranhão, em sítios estratégicos, localizados na interseção entre os cursos d?água e a floresta (CASTRO, 2008).

Já no século XX, o Estado passou a atuar de forma determinante nas estratégias de intervenção no território amazônico, com consequência na urbanização. Sob o discurso nacionalista o governo de Getúlio Vargas liderou a "Marcha para o Oeste" em 1938, que constituiu a primeira política oficial de ocupação do Centro-Oeste e Amazônia, incluindo aí a área de influência da BR-163. A Marcha era "o verdadeiro sentido de brasilidade". A floresta era um perigo a ser vencido e deveria ser ocupada (Torres et al., 2017).

Nesta toada, a criação da Superintendência do Desenvolvimento da Amazônia (SUDAM), criado em 1966, no governo de Castelo Branco, representou o eixo principal da política do Estado brasileiro para a região Amazônica. O principal objetivo da autarquia federal era a adoção de uma política de incentivos fiscais e creditícios com vistas a atrair capitais nacionais e internacionais para a região, bem como concentrar investimentos em áreas selecionadas e a definir espaços econômicos suscetíveis de desenvolvimento planejado. A partir dela viabilizou-se um fundo de investimentos (FINAM) e o Banco da Amazônia S/A (BASA), permitindo com que grandes grupos econômicos investissem em projetos agropecuários na Amazônia (CARDOSO \& MULLER, 2008).

Para Monteiro e Coelho (2004), este modelo de desenvolvimento econômico repercutiu nas dinâmicas sociais e ecológicas da região, acelerando a substituição das florestas e a ampliação da concentração fundiária, desencadeando problemas ambientais e sociais.

Os investimentos em transporte, por exemplo, foram direcionados para facilitar o escoamento da produção e a redução dos custos do transporte. O asfaltamento de diversas rodovias, como a BR-163 (Cuiabá-Santarém) e a BR-319 (Manaus-Porto Velho) objetivou facilitar o escoamento da produção agrícola e torná-la vantajosa economicamente. Tais facilidades econômicas consequentemente levaram ao desmatamento e ao conflito pela posse da terra em áreas de floresta. Vários estudos têm demonstrado o aumento do desmatamento nas áreas próximas a estradas (SUYÁ, et al., 2011). Ademais, acrescenta Costa (2001): 
Nas três últimas décadas, observou-se na Amazônia a expansão da agricultura mecanizada, representada pela soja. Essa expansão expressa um processo de longa duração que se iniciou na região Sul do Brasil e posteriormente irradiou-se para outros estados. A partir do estado do Mato Grosso, a soja é introduzida na Amazônia. (COSTA, 2001).

Ainda de acordo com Costa (2001), o fator preponderante para a expansão rápida das lavouras de soja nos estados amazônicos foi o grande "estoque" de terras, com características favoráveis à implantação das lavouras comerciais, a preços reduzidos. Explica o autor:

\begin{abstract}
O mercado de terra nas áreas de fronteira sofre grande influência da ação dos agentes locais, que atuam no sentido de reduzir a mobilização de capital na aquisição de novas áreas. Em uma análise preliminar, observa-se que a elevação dos custos de produção, pelo aumento dos preços de insumos, maquinários e transporte, é compensada pelo baixo custo de aquisição de terras em regiões de abertura recente, encontradas a preços bastante inferiores àqueles praticados em regiões consolidadas. (COSTA, 2001).
\end{abstract}

Construída durante a ditadura militar, até os anos 2000 a BR-163 permanecia relativamente adormecida. No entanto, em 2003, quando o então presidente Luís Inácio Lula da Silva anunciou seu asfaltamento, deu-se início a uma multiplicação de terminais portuários e a estrada se tornou o principal corredor para exportação de commodities como soja, milho e algodão produzidos em escala comercial no Mato Grosso.

Para Torres et al. (2017), o asfaltamento da BR-163 seria uma continuidade do discurso bandeirante pautado na lógica da conquista, por meio da apropriação de terras públicas, de apropriação de recursos públicos, da depredação e da violência. $\mathrm{O}$ asfaltamento da rodovia, sem dúvida, intensificou tais problemas.

\title{
2. O plano BR-163 sustentável e a Flona Jamanxim
}

A Flona Jamanxim, com 1,3 milhão de hectares, foi concebida dentro de um pacote de medidas, que se mostrou minuciosamente debatido e planejado, ao menos em tese. No período de 2004 a 2006, vários setores do governo federal, estaduais e municipais elaboraram em conjunto com a sociedade civil organizada e o setor privado o Plano de Desenvolvimento Sustentável da Área de Influência da BR-163.

De acordo com Ministério do Meio Ambiente (MMA) a área de proteção ambiental faz parte do Distrito Florestal Sustentável, tendo como limites a área de influência 
da rodovia BR-163, compreendida pela mesorregião do Vale do Jamanxim ao sul, até Santarém-PA ao norte, e o município de Jacareacanga-PA a oeste. Vejamos informações extraídas da página eletrônica oficial do MMA:

Distrito Florestal Sustentável

As ações do Projeto BR-163 fornecem subsídios e elementos para a efetivação do primeiro Distrito Florestal Sustentável (DFS) do Brasil, criado em fevereiro de 2006. O território do DFS compreende mais de 190 mil quilômetros quadrados, quase o tamanho dos Estados do Rio de Janeiro e Ceará juntos. O Distrito é cortado pela principal rodovia que vai do Norte do Mato Grosso ao Oeste do Pará, a BR 163 Cuiabá Santarém, aberta durante o governo militar em 1973. (Plano Br-163 Sustentável. Junho, 2006).

Entre as ações propostas no DFS estava a efetivação de unidades de conservação tanto de uso sustentável, como Florestas Nacional (Flonas) e Reservas Extrativistas (Resex), quanto de proteção integral, como Parques Nacionais e Reservas Biológicas. O plano teria por finalidade reduzir dos impactos socioambientais provocados pelo asfaltamento. Nesta perspectiva, concessões florestais seriam permitidas dentro de Florestas Nacionais (Flonas), categoria de UC que permite o uso sustentável de recursos naturais.

Para a Flona Jamanxim, além da inserção em um contexto macro de proteção da Amazônia, a finalidade também seria o desenvolvimento de atividades coordenadas de políticas públicas dos diversos setores do governo, de forma a fomentar a atividade florestal em bases sustentáveis: política fundiária, desenvolvimento industrial, de infraestrutura, ciência e tecnologia, assistência técnica e educação.

Reforçando a preocupação e compromisso social, o Plano BR-163 sustentável deixou claro a necessidade de um plano estratégico para que a pavimentação rodoviária não acarretasse prejuízos à floresta, a exemplo dos danos ambientais provocadas pelas políticas desenvolvimentistas em especial na década de 70 . Vejamos trecho destacado do referido Plano:

Não obstante seus potenciais benefícios sociais e econômicos, a pavimentação da rodovia Cuiabá-Santarém, na ausência de um plano estratégico, poderia agravar os impactos sociais e ambientais indesejáveis na sua área de influência. Esses impactos se relacionam ao aumento de migrações desordenadas, grilagem e ocupação irregular de terras públicas, concentração fundiária, desmatamento, queimadas, incêndios florestais e exploração não-sustentável dos recursos naturais, aumento da criminalidade e agravamento das condições de saúde pública, tudo isso 
agravado pela presença ainda insuficiente do poder público na região. (Plano Br-163 Sustentável. Junho, 2006).

Em que pese, o Plano BR 163 Sustentável tenha sido um acordo interministerial, no qual vários órgãos deveriam ter vindo para a região com intuito de garantir uma exploração sustentável. Na prática apenas ICMBio e IBAMA concentraram ações na localidade, ainda que com graves deficiências administrativas, que, na prática, tornaram inviáveis a fiscalização de 6,4 milhões de hectares de florestas protegidas.

Hoje, no entanto, a economia de muitas cidades em torno da Rodovia, a exemplo de Novo Progresso, área de inserção da Flona Jamanxim, tem sido fortalecida, muito provavelmente, com recursos advindos de crimes ambientais.

\section{O recuo ambiental institucional na proposta de alteração da Flona Jamanxim}

Embora as unidades de conservação nunca tenham sido efetivamente implementadas na região, no sentido disciplinado do ato de criação (Decreto Presidencial), ou no Plano BR-163 Sustentável, ainda assim, para Torres et al. (2017), o mosaico protetor contribuiu para a diminuição do desmatamento na Amazônia.

Os autores ora referenciados consideram que a mudança no status fundiário da terra provoca um efeito simbólico que ajuda a inibir o movimento do desmatamento. $\mathrm{O}$ fator de inibição está no fato de que as unidades de conservação passam a ser titularizadas como terras públicas federais, inviabilizando por si só qualquer tipo de ocupação legítima, ressalvadas as excepcionalidades legais. De acordo com o ICMBio aproximadamente 30 a 40 famílias deveriam ter sido indenizadas e realocadas, quando da criação da Flona em 2006.

No entanto, a referida área de proteção figura entre as unidades de conservação mais desmatadas, pois sua criação gerou forte oposição em setores da sociedade local, principalmente entre fazendeiros que haviam se apossado, ou adquirido terras de terceiros e grileiros, sem a devida documentação legal, e assim mantiveram enormes pretensões fundiárias na área que veio a se tornar a Flona Jamanxim. As especulações quanto à futura desafetação ou alteração tornou-se uma constante, acrescida ainda da ausência estatal em prover políticas sustentáveis para a região, culminaram no protago- 
nismo da FNJ entre as unidades de conservação mais desmatadas da Amazônia.

A Flona Jamanxim é a área de proteção mais próxima da BR-163, e com o asfaltamento da rodovia houve um aquecimento do mercado de terras "roubadas". Logo, as terras da Flona começaram a valer muito, e passaram a ser alvo de muita cobiça e consequentemente de muita pressão econômica e política. $O$ interesse pela desafetação se dá neste contexto - na apropriação de terras públicas para venda (TORRES, 2017, com. Pes.).

Oportuno enfatizar outro aspecto que está diretamente relacionado a tal interesse: a Flona Jamanxim encontra-se em uma região estratégica para o governo federal, estadual e local, dada as iniciativas da política de integração intermodal - construção de hidrovias, rodovias e ferrovias.

A malha intermodal viabilizará a abertura da chamada "Saída Norte", ou "Arco Norte". Para a Confederação Nacional de Agricultura (CNA) será possível reduzir em mais de $30 \%$ o custo do frete da produção de Mato Grosso a ser enviada ao exterior. A CNA destaca que da porteira da fazenda até o porto, o custo do transporte da produção brasileira é quatro vezes (4x) superior ao dos EUA, o que torna os grãos brasileiros mais caros na chegada à China, apesar do menor custo de produção.

A lógica econômica da abertura do Arco Norte está no fato de os portos da região serem mais próximos dos EUA, Europa e Ásia. A distância em navio entre o Porto de Itaqui (MA), por exemplo, e o Japão, via canal do Panamá, é 23\% menor do que o percurso entre o Porto de Santos (SP), de onde saem 85\% da produção agrícola do país, e Tóquio. Isso significa menos custo de combustível e menos tempo de viagem.

\section{4. $O$ cometimento de crimes ambientais}

A especulação para a alteração ou até mesmo a desafetação da Flona Jamanxim, referenciada acima, sem dúvida acentuou a tensão por conflitos fundiários, a partir de 2006. E não por acaso que, segundo dados oficiais do ICMBio, 68\% do desmatamento recente na Amazônia acontece nessa região. Em 2009 e 2010 foram realizadas pela Polícia Federal (PF) as operações Boi Pirata I e II. Nesta última operação, II, foram apreendidas centenas de cabeças de gado retiradas do interior da Flona Jamanxim, e com 
isso aplicadas multas equivalentes ao montante de milhões de reais. Os proprietários eram grandes fazendeiros da região.

Já em 2014, outra grande operação foi realizada pela PF em conjunto com o MPF e o IBAMA, denominada de "Operação Castanheira", em homenagem ao senhor Ezequiel Castanha, proprietário dos supermercados Castanhas. A sua principal fonte de lucros era a grilagem e a venda de terras públicas, engendradas por poderosas organizações criminosas.

Outra importante atuação policial foi deflagrada em 2016 pela PF, IBAMA e Receita Federal, a chamada operação "Rios Voadores", na qual foi desarticulada organização criminosa responsável pela conversão forçada de florestas em pastagens. Segundo as investigações, a organização era liderada pelo empresário Antônio José Junqueira Vilela Filho, conhecido como "AJ" ou "Jotinha". O grupo invadia a floresta, retirava e vendia a madeira de valor comercial mais alto, e depois derrubava a mata remanescente e ateava fogo.

De acordo com informações veiculadas pelo IBAMA, na terra devastada era plantado capim e instalada a criação de gado. Para praticar esses crimes a organização criminosa utilizava mão de obra submetida a condições análogas a de escravos. Após a consolidação das pastagens, o grupo registrava os terrenos em cadastros ambientais rurais oficiais. Os registros eram feitos em nome de laranjas (pessoas que serviam como intermediárias em negócios fraudulentos). As pastagens, então, eram exploradas pelos próprios integrantes do grupo ou arrendadas para terceiros.

O sistema criminoso movimentou $\mathrm{R} \$ 1,9$ bilhão entre 2012 e 2015 e destruiu 300 km quadrados de florestas em Altamira, no Pará. O prejuízo ambiental foi de $R \$ 420$ milhões. Por essas e outras irregularidades, Jotinha é o infrator que recebeu as maiores multas já aplicadas pelo IBAMA na Amazônia ( $R$ \$ 120 milhões em dez autos de infração), sendo o responsável pela maior área já embargada pela autarquia na região (300 km quadrados).

Torres et al. (2017) alerta, contudo, que o desmatamento e a criação de boi não são atividades produtivas. E sim instrumento de grilagem. No livro "Dono é quem desmata" os autores descrevem que na região sudoeste do Pará a lógica consiste no re- 
conhecimento de que o dono da terra é aquele que desmata - "Depois de desmatada a terra valoriza até 50x, e então o saqueador a vende". O desmatamento é instrumento de empoderamento, de saqueio de terras públicas. O grileiro comercializa a partir do Cadastro Ambiental Rural (CAR), que tem cunho meramente declaratório. Porém, quando inquerido pela documentação da terra, o grileiro informa que possui o $\mathrm{CAR}^{4}$.

A expectativa reside, no entanto, nas flexibilizações oportunizadas pelo governo federal, a exemplo do Programa Terra Legal, ou até mesmo na sanção da MP 759, convertida na Lei $n^{\circ} 13.465 / 2017$, publicada no dia 12/07/2017 no Diário Oficial da União (TORRES, 2017. com. Pes.).

A lei propõe garantir efetividade na aplicação do Programa Terra Legal, a partir de um modelo menos burocrático, mais transparente e ágil. Segundo o Governo, o novo formato corrige irregularidades do passado e garante ao trabalhador rural assentado o direito de acesso às políticas públicas da agricultura familiar. Para o secretário Especial de Agricultura Familiar e do Desenvolvimento Agrário, José Ricardo Roseno o Governo está modernizando a regularização fundiária no País e o Programa Terra Legal, com foco na titulação.

Bem, resta saber quem serão de fato os beneficiados com a agilização e a flexibilização, ao menos, no contexto da Flona Jamanxim, caso o projeto de Lei 8.107/2017 seja aprovado, e a haja a alteração dos limites territoriais desta unidade de conservação nas proporções desejadas pela banca ruralista no Congresso Nacional.

\section{As incursões para alteração em Brasília}

Como visto acima, o Governo enviou ao Congresso um novo Projeto de Lei (8.107/17) propondo novamente reduzir 350 mil hectares $(26,45 \%)$ da área de proteção da Floresta Nacional (Flona) de Jamanxim, no sudoeste do Pará, transformando-a em Área de Proteção Ambiental (Figura 2 ilustra as alterações consignadas no referido projeto de lei). A mudança de categoria para $\mathrm{APA}^{5}$ permite atividades de agropecuária,

\footnotetext{
${ }^{4} \mathrm{O}$ CAR é feito pela Secretaria do Meio Ambiente do Estado do Pará, sendo apenas uma via provisória e de cunho declaratório. O CAR na versão definitiva demanda outros documentos comprobatórios.

${ }^{5} \mathrm{O}$ artigo $15, \S \S 1^{\circ}$ a $5^{\circ}$ do SNUC - Área de Proteção Ambiental (APA) é a unidade de conservação que poderá ser formada por áreas públicas ou particulares, em geral extensas, com certo grau de ocupação humana, com atributos bióticos ou mesmo culturais, visando proteger a diversidade biológica, disciplinar o
} 
atividade industrial, mineração, ocupação urbana e rural, o que pode contribuir para o desmatamento da floresta.

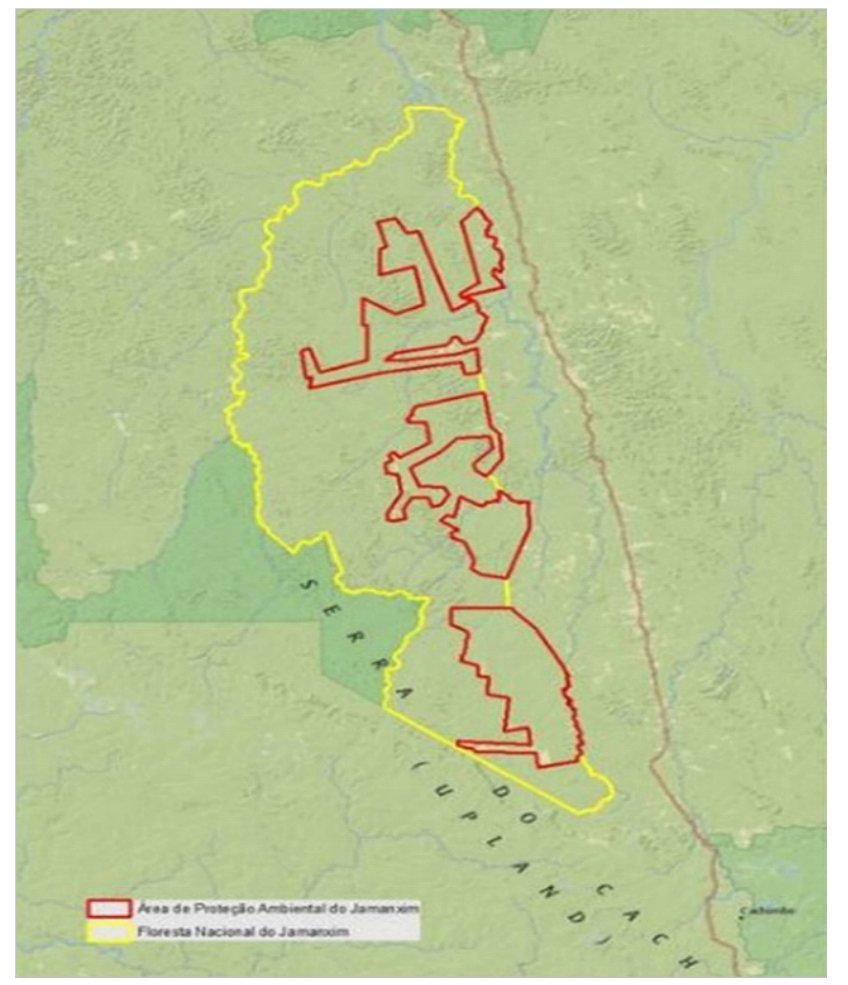

Figura 2. Proposta de redução da Flona Jamanxim - Projeto de Lei 8.107/2017. Fonte: Instituto Socioambiental - ISA.

Porém, antes do Projeto de Lei ser proposto, o Poder Executivo Federal já havia cedido a pressões para modificações da área. É sabido que para viabilizar a ferrovia que escoará soja de Lucas do Rio Verde (MT) para Miritituba (Itaituba/Pa) seria necessário alterar unidade de conservação na região, uma vez que a ferrovia iria se sobrepor a área protegida.

Segundo o Instituto de Socioambiental (ISA) inicialmente a proposta de Medida Provisória previa 862 hectares necessários para a transposição da Ferrogrão. No entanto, para garantir a aprovação junto ao Congresso Nacional, o Governo teve que barganhar com alguns progressistas, que em troca exigiram outra MP com alteração de 305 mil hectares em outra unidade de conservação. O acordo foi feito e então nasceu no dia 19/12/2016 as MP 756/2016 e MP 758/2016. Ao longo da tramitação o que se viu no Congresso Nacional foi um alvoroço de emendas parlamentares com pedidos de des- 
proteção da floresta e o que tinha inicialmente sido proposto pelo Executivo, de 305 mil hectares, estava indo para 1,2 milhões de hectares. Justamente no lugar da Amazônia mais sensível e no momento que o desmatamento voltava a crescer.

A MP 756/2016 (vetada integralmente) alterava os limites do Parque Nacional do Rio Novo (localizado em Itaituba e Novo Progresso) e da Floresta Nacional do Jamanxim (situada em Novo Progresso), desmembrando parte de sua área para a criação da Área de Proteção Ambiental (APA) Jamanxim. E a MP 758/2016 (vetada parcialmente) alterava os limites do Parque Nacional do Jamanxim e criava a Área de Proteção Ambiental Rio Branco para dar passagem à Estrada de Ferro 170 (EF) - encontra-se em trâmite para o procedimento licitatório -, e próxima a BR-163, e será responsável por escoar soja de Lucas do Rio Verde (MT) à Miritituba (Itaituba/Pa).

Destaca-se que os vetos ocorreram às vésperas da viagem do presidente Michel Temer à Noruega, onde trataria de questões ambientais ${ }^{6}$. Posteriormente, recuou e cedeu, provavelmente, à pressão de produtores rurais do Pará, que chegaram a promover bloqueios na BR-163 (Cuiabá - Santarém).

Entre os argumentos, no discurso oficial estatal, o Projeto de Lei (na fala do Ministério do Meio Ambiente) será para "proteção da diversidade biológica, disciplinamento do processo de ocupação da região e fomento ao manejo florestal sustentável e a conservação dos recursos hídricos".

No tocante à justificativa de regulamentação da ocupação na região, interessante destacar trechos do Estudo Técnico de Revisão dos Limites da Floresta Nacional do Jamanxim, concluído no final de setembro de 2009, pelo ICMBio:

O anseio pela redefinição dos limites da Flona Jamanxim envolve questões históricas de ocupação da terra que remonta basicamente à década de 1980, e consequentemente as discussões preliminares propostas com fulcro na alteração da UC não refletiriam a realidade sócio-

\footnotetext{
${ }^{6}$ Talvez a pressão mais contundente foi a Carta enviada pela Noruega ao Ministro do Meio Ambiente, Sarney Filho, às vésperas da viagem do presidente Temer a Alcos, na Noruega. A carta manifestava preocupação com o crescimento de índices de desmatamento na Amazônia, por apresentar políticas públicas contraditórias com a preservação ambiental, a exemplos das MPs, e assim o descumprimento do acordo firmado com o Brasil, que se comprometerá com combate ao desmatamento, em troca do aporte financeiro do país norueguês ao Fundo da Amazônia para projetos com esta finalidade. A Noruega é o maior investidor do referido fundo e desde 2008 investiu mais de 2, 8 bilhões. Não obstante, durante a visita do Temer à Noruega, fora anunciado o corte de $50 \%$ do valor que seria repassado para o Brasil em 2017. Vale ressaltar que parte do recurso do Fundo é direcionado ao IBAMA. (Portal iG São Paulo, 2017).
} 
econômica e fundiária locais. (Relatório final, 2009, ICMBio).

Neste sentido, o documento alerta para as soluções de cunho imediatista, pois atenderiam a interesses corporativistas ligados a alguns latifundiários, talvez, os maiores interessados na redução, em grandes proporções, dos limites atuais da unidade de conservação.

\begin{tabular}{l} 
Na Flona Jamanxim tentou-se replicar o modelo de ocupação das \\
terras do estado de Mato Grosso através de associações que da- \\
riam destinação de posses a pretensos interessados, principal- \\
mente para a implantação da pecuária extensiva em áreas ao longo \\
da Rodovia BR -163, onde localiza-se a Flona Jamanxim. E, desde \\
1983 até a criação da unidade, não foram devidamente regulariza- \\
das junto ao órgão competente, apesar de muitos posseiros ha- \\
verem protocolado pedidos junto ao INCRA, órgão fundiário res- \\
ponsável pelas áreas. Objetivamente não existem proprietários com \\
terras registradas em cartório dentro dos limites da Flona Jamanxim, \\
\hline existem apenas posseiros, basicamente com documentos de compra e \\
\hline venda, com pretensões fundiárias quase que exclusivamente de grandes \\
\hline extensões, com alta concentração fundiária, e refletem uma ocupação \\
\hline voltada à pecuária extensiva, nada comprometida com as questões \\
\hline sócio-econômicas locais. (Relatório final, 2009, ICMBio). (Grifo do au- \\
\hline tor).
\end{tabular}

O Estudo feito pelo ICMBio em 2009 é categórico ao afirmar que reduzir drasticamente a Flona Jamanxim não é a solução:

Isto [a redução drástica] levaria a um recuo de estratégia governamental de conservação que traria consequências ambientais imprevisíveis não só para a própria área da Flona, mas também para várias outras unidades de conservação da Amazônia, invariavelmente sofrendo de pressão fundiária, invasões e interesses políticos. (Relatório final, 2009, ICMBio). (Grifo do autor).

Dados do ICMBio apontam que $67 \%$ das detenções de terras instalaram-se depois da criação da Flona, e 60\% desses ocupantes não residiam na área. O estudo proferido pelo órgão gestor em 2009 enfatizava que os benefícios sociais da redução seriam mínimos, já que eram poucas as famílias que viviam na região antes de 2006: cerca de 30 a 40 famílias em toda a extensão da unidade. Senão vejamos outro trecho do relatório:

Em algumas das fazendas mantêm-se vaqueiros, mas muitas áreas não possuem ninguém, e nem pastagens, são vastas extensões de florestas públicas, que apesar desta condição tem posseiros que se dizem donos. Encontram-se também muitos pastos abandonados, em processo natural de regeneração. (Relatório final, 2009, ICMBio). (Grifo do autor).

Estudos do Instituto do Homem e Meio Ambiente da Amazônia (Imazon) afirmam ainda que a área média dessas pretensões é de 1.843 hectares, escala muito 
acima das ocupações médias dos colonos da região. Em parecer técnico o órgão gestor informa que a Flona Jamanxim tem cerca de 300 domicílios registrados, sendo que grande parte das posses são de fazendas de pecuárias, ocupadas após a criação da Flona (2006), o que seria ilegal.

Em conclusão o estudo técnico realizado em 2009 é enfático ao defender a desafetação de três áreas da Floresta que totalizaria 35 mil hectares, contudo alertou que a pressão para diminuir a unidade continuaria:

\begin{abstract}
Certamente as três áreas propostas para desafetação por este trabaIho não satisfarão os anseios dos fazendeiros e políticos que propõe a desconstituição da unidade, porém são os únicos possíveis ajustes que não trarão os prejuízos sociais e ambientais expostos. Ressalta-se que a concessão florestal proposta para a Flona Jamanxim indubitavelmente trará maiores benefícios sociais e ambientais do que o atual modelo de grandes propriedades com pecuária extensiva. (Relatório final, 2009, ICMBio). (Grifo do autor).
\end{abstract}

O Ministério Público Federal (MPF) expediu a Recomendação $n^{\circ} 25$, de 12/08/2016, ao ICMBio, e impetrou a Ação Cível Pública nº 0001990-15.2016.4.01.3908 (datada de 10/11/2016), ambas com a finalidade de sustar processo administrativo, que tivesse por objeto a recategorização e/ou desafetação da unidade de conservação, sem o devido trâmite legal. Em resposta, o ICMBio justificou a alteração diante do aumento do desmatamento na unidade e "esgotamento das ferramentas de comando, controle e gestão disponíveis para a Instituição enfrentar esta situação", além da antiguidade das reivindicações para a alteração.

Então, há uma indicação do órgão gestor, ICMBio, no sentido de que o problema quanto às ocupações irregulares de fato permanece. O perfil fundiário continua dominado por posseiros e grileiros sem título de posse (ao menos antes da MP 759, convertida na Lei $n^{\circ}$ 13.465/2017). A dificuldade reside, desde 2006, na falta de condições administrativas associado com a ausência de políticas públicas, ao menos nos termos do que foi consignado no Plano BR-163 Sustentável. E isso contribuiu indubitavelmente para o cometimento de crimes ambientais e o aumento da violência na região.

O PL em trâmite, no entanto, evidencia que o ICMBio mudou seu posicionamento e sinalizou parecer favorável para reduzir além do recomendado em 2009. Segundo informações veiculadas no sítio oficial da Câmara dos Deputados a área da floresta sairá 
dos atuais 1,32 milhão de hectares (pouco mais do dobro do tamanho do Distrito Federal) para 953 mil hectares. E a APA terá outros 349 mil hectares $^{7}$ (26,45\% da área original da Flona, pouco acima de duas vezes o município de São Paulo), dividida em quatro áreas diferentes. O PL condiciona no art. $3, \S 2^{\circ}$ que o morador que estiver na APA deve comprovar ocupação e exploração da área antes de 13 de fevereiro de 2006:

\section{Art. $3^{\circ}(\ldots)$}

$\S 2^{\circ}$ As ocupações incidentes na Área de Proteção Ambiental do Jamanxim poderão ser regularizadas em conformidade com a legislação fundiária, respeitados a fração mínima de parcelamento e o limite de módulos fiscais, nos termos de seu plano de manejo e desde que comprovado o exercício de ocupação e exploração direta, mansa e pacífica, por si ou por seus antecessores, anteriormente a 13 de fevereiro de 2006. (PL n 8107/17).

Interessante ressaltar que para o Instituto de Pesquisa Ambiental da Amazônia (Ipam) outras APAs, especialmente no litoral do país, de fato estão cumprindo as restrições de uso. Mas na Amazônia, porém, dadas as dificuldades de fiscalização e a própria leniência do governo em fazer valer o Código Florestal, tais restrições tendem a não ter efeito contra o desmatamento. Na Amazônia, as taxas de desmatamento em APAs são idênticas às das áreas privadas.

\section{Considerações finais}

Sem dúvida a unidade de conservação é um instrumento que pode inibir o desmatamento, pois retira terras públicas da possibilidade de grilagem. Porém, quando o próprio governo reduz uma área protegida para beneficiar a grilagem, certamente, fomenta um efeito dissuasório, com possíveis impactos em outras áreas protegidas.

Vimos que o discurso do desenvolvimento sustentável, por meio de plano de manejo e concessões florestais, infelizmente tem se mostrado utópico, a exemplo do Plano BR-163 Sustentável. Na prática as unidades de conservação sequer foram implementadas, e ainda que o ato de criação seja inibitório ao avanço do desmatamento, a ausência de investimentos contundentes para o gerenciamento de áreas como a Flona Jaman-

\footnotetext{
${ }^{7}$ O percentual de floresta transformado em APA é menor que o previsto na Medida Provisória 756/16, que foi vetada pelo presidente Michel Temer em 20 de junho, após críticas de organizações ambientais. $O$ texto original da MP estabelecia que $41 \%$ da floresta viraria área de preservação, enquanto o texto alterado pelo Congresso transformava 37\% da floresta em APA. (Assessoria Câmara dos Deputados, 2017).
} 
xim, que excede a 1 milhão de hectares, torna-se um fator decisivo para o avanço do desmatamento e o cometimento de crimes ambientais.

Neste cenário, as terras próximas à BR-163, que formam uma rica biodiversidade representativa de importantes biomas brasileiros, por meio de áreas de florestas contíguas preservadas nas unidades de conservação, começam a ser um obstáculo em superação, a partir da Flona Jamanxim. A velha lógica de ocupação da Amazônia, por meios que privilegiam o capital, tendem a se perpetuar e determinam as regras do jogo, ainda que em áreas tão sensíveis da sociedade, como o meio ambiente.

Então, a fatídica conclusão emerge: a própria ausência do Estado, omisso em uma repressão atuante e ações efetivas, está sendo substituída por uma resolutividade prejudicial ao bem jurídico protegido constitucionalmente, e em prol de grandes latifundiários (beneficiados com a flexibilização de regularização de terras na Amazônia).

Não podemos olvidar que o PL 8.107/17 abre precedente perigoso de incentivo à grilagem e ao desmatamento ilegal, criando a expectativa de que as posses ilegais podem ser anistiadas. Mas outro questionamento surge e permanece em aberto: haverá o cumprimento efetivo de eventuais condicionantes impostas no referido PL, conforme destacado no art. $3, \S 2^{\circ}$ ? Cabe a sociedade acompanhar e intervir ativamente, pois o precedente de desproteção é grave e poderá trazer efeitos catastróficos e irreversíveis a toda a coletividade e ao meio ambiente.

\section{Referências}

AMADO, Frederico. Direito Ambiental. 8ª ed. Salvador, Bahia: Juspodivm, 2017.

BENJAMIN, Antônio Herman V. Direito Constitucional Ambiental Brasileiro, p. 90, In: CANOTILHO, J.J Gomes e LEITE, José Rubens Morato (Org.). Direito Constitucional Ambiental Brasileiro. 4ª ed. São Paulo: Saraiva, 2011.

CANOTILHO, José Joaquim Gomes. Direito Constitucional Ambiental. 1994.

CARDOSO, F. H.; MÜLLER, G. Amazônia: expansão do capitalismo [online]. Rio de Janeiro: Centro Edelstein de Pesquisas Sociais, 2008.168 p. ISBN: 978-85-99662-73-1. Available from. SciELO Books <http://books.scielo.org>.

CASTRO, Edna. Urbanização, pluralidade e singularidades das cidades amazônicas. In: , Edna (org.). Cidades na floresta. São Paulo: Annablume, 2009, p. 13 - 39.

COSTA, S. M. G. da. Agronegócio e terras na Amazônia: conflitos territoriais e desterritorialização após a chegada da soja na região do Baixo Amazonas no Pará. In: SAUER, 
Sérgio e ALMEIDA, Wellington (org.). Terras e territórios na Amazônia: demandas, desafios e perspectivas. Brasília: Edunb, / Abaré Editorial, 2001, p. 69 - 89

LÖWY, Michael. Walter Benjamin: aviso de incêndio: uma leitura das teses. In: Sobre o conceito de história. Tradução de Wanda Nogueira Caldeira Brant. Tradução das teses de Jeanne Marie Gagnebin e Marcos Lutz Müller; São Paulo: Boi tempo, 2005.

MONTEIRO, M.de A.; COELHO, M. C. N. As políticas federais e reconfigurações espaciais na Amazônia. Novos Cadernos NAEA. v. 7, n. 1, p. 91-122, jun. 2004.

SUYÁ, Q.; BOHRER, C. B. A.; IRVING, M. A. Políticas Públicas Para A Amazônia: Práticas E Representações Em Disputa. Rde - Revista De Desenvolvimento Econômico. Ano Xiii $n^{\circ} 23$ Julho de 2011 Salvador, Ba.

THOMÉ, Romeu; MEDEIRO, Leonardo de. Leis Especiais para Concurso. $4^{\mathrm{a}}$ ed. Rio Grande do Norte: Juspodvium, 2016.

TORRES, M.; DOBLAS, J. e ALARCON, F. D. "DONO É QUEM DESMATA". Conexões entre grilagem e desmatamento no sudoeste paraense. São Paulo: Urutubranco; Altamira: Instituto Agronômico da Amazônia, 2017. Link para acesso: https://www.socioambiental.org/sites/blog.socioambiental.org/files/nsa/arquivos/ dono_e_quem_desmata_conexoes_entre_gril1.pdf

BRASIL. Medida Provisória $\mathrm{n}^{\circ}$ 756, de 19 de dezembro de 2016. Dispõe sobre alteração dos limites do Parque Nacional do Rio Novo, da Floresta Nacional do Jamanxim e cria a Área de Proteção Ambiental do Jamanxim. Disponível em: http://www.planalto.gov.br/ccivil_03/_ato2015-2018/2016/Mpv/mpv756.htm. Acessado em 27.03.2017

BRASIL. Ação Cível Pública n 0001990-15.2016.4.01.3908. Ministério Público Federal de Itaituba, Pará. Disponível em: http://www.mpf.mp.br/pa/sala-deimprensa/documentos/2016/acao-do-mpf-pela-nao-reducao-da-flona-do-jamanximsem-estudos-e-consulta-publica. Acessado em 27.03.2017

BRASIL. Lei $\mathrm{n}^{\circ}$ 9.985, de 18 de julho de 2004. Regulamenta o art. 225, § 10, incisos I, II, III e VII da Constituição Federal, institui o Sistema Nacional de Unidades de Conservação da Natureza e dá outras providências. Disponível em: http://www.planalto.gov.br/ccivil_03/leis/L9985.htm“://www.planalto.gov.br/ccivil_03/ leis/L9985.htm. Acessado em 27.03.2017

BRASIL. Recomendação no 25/2016, de 12 de agosto de 2016. Ministério Público Federal de Itaituba, Pará. Disponível em: http://www.mpf.mp.br/pa/salade-imprensa/documentos/2016/recomendacao_25_ic-10-2014-29_limite-flona-

jamanxim.pdf. Acessado em 27.03.2017

Assessoria de Comunicação do IBAMA. Operação desarticula quadrilha de desmatadores que movimentou $R \$ 1,9$ bi do Pará. Disponível em: http://www.ibama.gov.br/noticias/58-2016/147-operacao-desarticula-quadrilha-dedesmatadores-que-movimentou-r-1-9-bi-no-para. Acesso em 07 jan. 2018.

Assessoria de Comunicação do MDA. MP 759 permitirá a entrega de 27 mil título rurais e urbanos até 2018. Disponível em: http://www.mda.gov.br/sitemda/noticias/mp-759permitir\%C3\%A1-entrega-de-27-mil-t\%C3\%ADtulos-rurais-e-urbanos-at\%C3\%A9-2018. 
Acesso em 07 jan. 2018.

Assessoria de Comunicação da Câmara dos Deputados. Projeto de Lei 8107/2017. Disponível em: http://www.camara.gov.br/proposicoesWeb/

prop_mostrarintegra;jsessionid=14B71CD0C98F3BB57B9340F2E882713D.

proposicoesWebExterno1?codteor $=1579401 \&$ filename $=P L+8107 / 2017$. Acesso em 07 jan. 2018.

MIRANDA, Thiago. Projeto do governo reduz Floresta Nacional do Jamanxim. Disponível em: http://www2.camara.leg.br/camaranoticias/noticias/MEIO-AMBIENTE/538036PROJETO-DO-GOVERNO-REDUZ-FLORESTA-NACIONAL-DO-JAMANXIM.html. Acesso em 07 jan. 2018.

Boletim Ambiental. Projeto Reduz Proteção À Flona. Disponível em: http://www.boletimambiental.com.br/noticia/2017-08-01/projeto-reduz-protecao-afloresta/. Acesso em 07 jan. 2018.

Instituto Chico Mendes de Biodiversidade. ICMBio. Estudo Técnico de Revisão dos limites da Floresta Nacional do Jamanxim. Daniel Cohenca. Coordenador da Equipe Técnica. Brasília, Setembro de 2009. Disponível em: https://documentacao.socioambiental.org/noticias/anexo_noticia/11685_ 20100503_170047.pdf. Acesso em 07 jan. 2018.

PORTAL iG SÃO PAULO. Mesmo com visita de Temer, Noriega corta pela metade recursos para Amazônia. Disponível em: http://ultimosegundo.ig.com.br/brasil/2017-0622/noruega-cortes-brasil.html. Acesso em 07 jan. 2018.

Assessoria de Comunicação do MMA. Projeto BR-163 Sustentável. Disponível em: http://www.mma.gov.br/florestas/projeto-br-163. Acesso em 07 jan. 2018. Instituto Socioambiental. Michel Temer quer criar a Floresta do 'Desmanxim'. Disponível em: https://www.socioambiental.org/pt-br/blog/blog-do-isa/michel-temerquer-criar-a-floresta-do-desmanxim. Acesso em 07 jan. 2018. 